\title{
DIFFERENCES IN ENERGY FLOW IN THREE DIRECTIONS IN HUMAN-TOOL BIOMECHANICAL SYSTEMS BASED ON SPATIAL HUMAN PHYSICAL MODELS SPECIFIED IN THE ISO 10068:2012 STANDARD
}

\author{
Marian Witalis Dobry, Tomasz Hermann \\ Poznan University of Technology, Institute of Applied Mechanics, Poznań, Poland \\ e-mail: marian.dobry@put.poznan.pl; tomasz.hermann@put.poznan.pl
}

\begin{abstract}
The article presents the differences in energy flow for two human physical models from ISO 10068:2012. The models are compared on the basis of a numerical simulation of energy flow implemented with MATLAB/simulink software. For purposes of comparison, the dynamics of the two Human-Tool systems is mathematically modelled and then used to derive their energy models. The model dynamic structures are fully specified in order to determine and compare three kinds of powers. The study revealed differences between the model characteristics when analysed along different directions of vibrations and as a whole.
\end{abstract}

Keywords: biomechanical system, energy flow, hand-arm vibrations

\section{Introduction}

Every physical model of a system requires a corresponding mathematical model. Developing a valid mathematical model is essential for purposes of analysing the system behaviour in different conditions (Cannon, 1973; Żółtowski, 2002). The construction of an appropriate model is not an easy task and should always be preceded by numerous verification studies. In an effort to create more complex models, it is sometimes more practical to take advantage of a model that has already been verified and use it as a component of a larger system. This approach may prove problematic when there is a number of competing models that can be used to describe a given system and each one is supposed to correctly represent the way the system functions. This is the kind of problem we are faced with when trying to choose a model representing responses of the human body to mechanical vibrations (Dobry and Hermann, 2014, 2015).

Research focused on developing discrete models of the human body dates back to the 1970s. Major contributions in this area were made in the studies by Griffin (1990), Meltzer (1981), Reynolds and Soedel (1972) and many others. Nowadays the impact of vibrations on the human body can be analysed by selecting one of many existing biomechanical models of the hand or the hand-arm system (Dobry and Hermann, 2014; Książek, 1996; Rakheja et al., 2002; ISO 10068:1998 and ISO 10068:2012). It is worth pointing out that in order to create a physical model, and hence a mathematical model of a system, one needs to have a wide knowledge of its structure and properties as well as relationships and processes that occur within it. It should also be remembered that a model is, by definition, a certain idealised or simplified representation of reality (Cannon, 1973; Żółtowski, 2002). This is exactly the kind of situation we are facing when trying to choose a model to analyse theoretically the impact of vibration on the human body. The available models differ from one another with respect to the number of components included in their dynamic structure, the kinds of joints and the number of degrees of freedom. This affects the extent to which the reality is simplified and the way the components are connected. Figure 1 shows selected structures of human biomechanical models used in the dynamic analysis of the 
impact of local vibrations. What is more, the character and the degree of simplification is related to the knowledge, awareness and needs of the researcher. Finally, it should be added that in this case all models must presuppose the same characteristic of motion of the model and the real system.

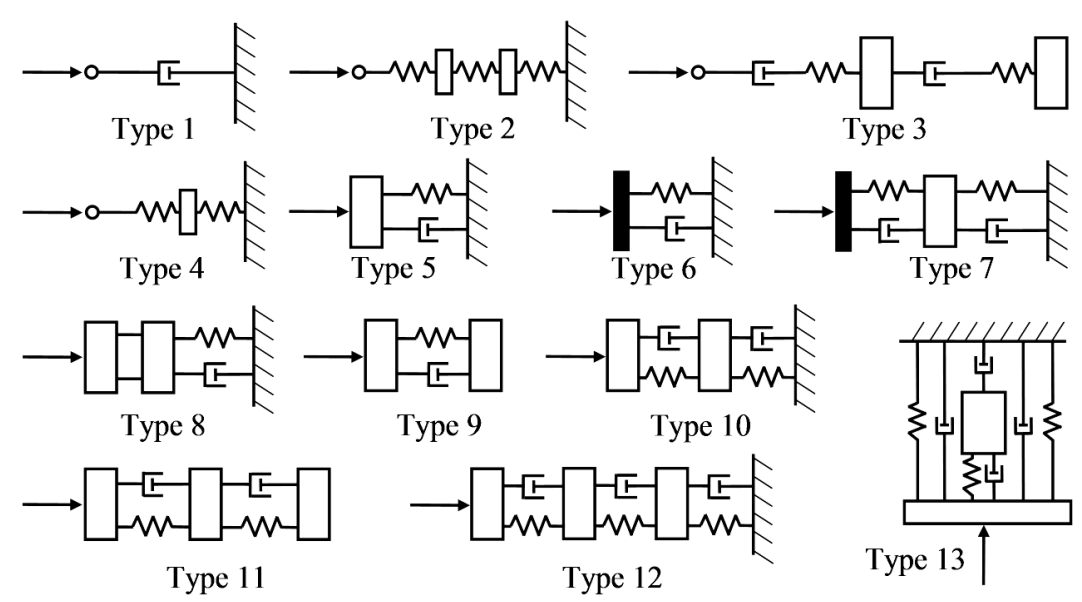

Fig. 1. Structures of human biomechanical models used to analyze the impact of local vibrations

(Książek, 1996)

Hence, while constructing a model, it is, above all, necessary to ensure the same response of the model and the real system to the excitation. However, the model should not be determined only on the basis of the relationship between input and output values or else the system to be analysed will resemble a black box. As a result, any conclusions drawn from such a model will most likely be imprecise, especially with respect to the impact of vibrations on the human body. It can be demonstrated that a system modelled with this approach disregards some unknown properties. Hence, while the response of the model is important, what also needs to be taken into account is adequate internal structure of the model. Only this kind of similarity between the model and the original system can ensure the most accurate information (Źółtowski, 2002).

Consequently, one can ask what distinguishes the models used to analyse the human response to mechanical vibrations? This question is particularly justified when one considers that the relevant standards, ISO 10068:1998 and ISO 10068:2012, contain a number of different human physical models. The fact is that work on the development of new models (ISO 10068:2012) has been conducted for a few years and presented in numerous publications, e.g. (Dong et al., 2007, 2010, 2013). Models described in the withdrawn standard ISO 10068:1998 have also been verified and approved and have been in use all over the world for many years. The facts mentioned above may help to appreciate the complex nature of modelling and model verification and the difficulty faced by those who need to choose one of the available models.

The present article describes an energy method used for comparative assessment of human physical models, specifically the Human-Tool model. The application of this procedure facilitates a comparison of the biomechanical Human-Tool systems (Dobry, 1998, 2001, 2012; Dobry and Herman, 2014). It is a synchronous method, in which values resulting from the dynamic analysis are used in real time as the input in the energy analysis. By applying an energy model of the system, it is possible to switch from the conventional dynamic analysis to the energy analysis conducted in the domain of energy flow. In the present study, the criterion for assessing the model validity is the equality of energy phenomena occurring in the dynamic structure during operation (Dobry, 1998, 2001, 2012; Dobry and Herman, 2014). The aim of the study is to analyse two models of the Human-Tool system, which are constructed using the physical models specified in ISO 10068:2012 - models 1 and 2. 


\section{Energy models of Human-Tool systems}

Physical models of the Human-Tool systems are constructed using human dynamic models from ISO 10068:2012. The models specified in the standard are discrete models, where specific points of reduction are connected by means of spring and damping systems. Basic parameters of the models are specified in ISO 10068:2012 - see Table 1 and 2.

The Human-Tool systems in question are constructed by combining human models with tool models. The purpose of the modelling process is to create a simple model of a person operating a power tool, e.g. an angle grinder. For this purpose, the energy analysis needs to account for the tool mass $m_{N}$, its vibration frequency $f$ and the character of the driving force $F(t)$.

Table 1. Values of dynamic parameters for the model with two points of reduction - model 1 (ISO 10068:2012)

\begin{tabular}{|c|c|c|c|c|}
\hline \multirow{2}{*}{ Parameter } & \multirow{2}{*}{ Unit } & \multicolumn{3}{|c|}{$k$-th direction of vibration } \\
\cline { 3 - 5 } & & $x$ & $y$ & $z$ \\
\hline \hline$m_{1 k}$ & $\mathrm{~kg}$ & 0.5479 & 0.5374 & 1.2458 \\
\hline$m_{2 k}$ & $\mathrm{~kg}$ & 0.0391 & 0.0100 & 0.0742 \\
\hline$k_{1 k}$ & $\mathrm{~N} / \mathrm{m}$ & 400 & 400 & 1000 \\
\hline$k_{2 k}$ & $\mathrm{~N} / \mathrm{m}$ & 0 & 17648 & 50000 \\
\hline$c_{1 k}$ & $\mathrm{~N} \cdot \mathrm{s} / \mathrm{m}$ & 22.5 & 38.3 & 108.1 \\
\hline$c_{2 k}$ & $\mathrm{~N} \cdot \mathrm{s} / \mathrm{m}$ & 202.6 & 75.5 & 142.4 \\
\hline
\end{tabular}

Table 2. Values of dynamic parameters for the model with three points of reduction - model 2 (ISO 10068:2012)

\begin{tabular}{|c|c|c|c|c|}
\hline \multirow{2}{*}{ Parameter } & \multirow{2}{*}{ Unit } & \multicolumn{3}{|c|}{$k$-th direction of vibration } \\
\cline { 3 - 5 } & & $x$ & $y$ & $z$ \\
\hline \hline$m_{1 k}$ & $\mathrm{~kg}$ & 0.4129 & 0.7600 & 1.1252 \\
\hline$m_{2 k}$ & $\mathrm{~kg}$ & 0.0736 & 0.0521 & 0.0769 \\
\hline$m_{3 k}$ & $\mathrm{~kg}$ & 0.0163 & 0.0060 & 0.0200 \\
\hline$m_{4 k}$ & $\mathrm{~kg}$ & 0.0100 & 0.0028 & 0.0100 \\
\hline$k_{1 k}$ & $\mathrm{~N} / \mathrm{m}$ & 400 & 500 & 1000 \\
\hline$k_{2 k}$ & $\mathrm{~N} / \mathrm{m}$ & 200 & 100 & 12000 \\
\hline$k_{3 k}$ & $\mathrm{~N} / \mathrm{m}$ & 4000 & 4907 & 43635 \\
\hline$k_{4 k}$ & $\mathrm{~N} / \mathrm{m}$ & 8000 & 17943 & 174542 \\
\hline$c_{1 k}$ & $\mathrm{~N} \cdot \mathrm{s} / \mathrm{m}$ & 20.0 & 28.1 & 111.5 \\
\hline$c_{2 k}$ & $\mathrm{~N} \cdot \mathrm{s} / \mathrm{m}$ & 100 & 39.7 & 39.3 \\
\hline$c_{3 k}$ & $\mathrm{~N} \cdot \mathrm{s} / \mathrm{m}$ & 144.6 & 50.7 & 86.8 \\
\hline$c_{4 k}$ & $\mathrm{~N} \cdot \mathrm{s} / \mathrm{m}$ & 79.9 & 14.3 & 121.0 \\
\hline
\end{tabular}

In the study, the tool model is limited to one mass $m_{N}=5 \mathrm{~kg}$. To enable comparisons between the models, it is assumed that a sinusoidally varying driving force $F(t)$ with an amplitude of $200 \mathrm{~N}$ acts on the biomechanical systems in every direction. This kind of force is usually generated in angle grinders due to mechanical wear. The last parameter, namely the vibration frequency, is set at $f=30 \mathrm{~Hz}$ and is taken into account in the driving force. Figure 2 shows the final models of the Human-Tool systems. 
The following step involves development of mathematical models of the dynamic structures using Lagrange equations of the second kind given by (Cannon, 1973; Żółtowski, 2002)

$$
\frac{d}{d t}\left(\frac{\partial E}{\partial \dot{q}_{j}}\right)-\frac{\partial E}{\partial q_{j}}=Q_{j}+Q_{j P}+Q_{j R} \quad j=1,2, \ldots, s
$$

where $E$ is the kinetic energy of the system, $q_{j}$ - generalized coordinates, $\dot{q}_{j}$ - generalized velocities, $Q_{j}$ - external active forces, $Q_{j P}$ - potential forces, $Q_{j R}$ - forces of dissipation, $s-$ number of degrees of freedom.

(a)

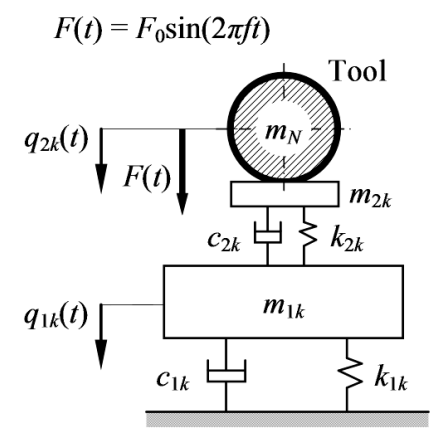

(b)

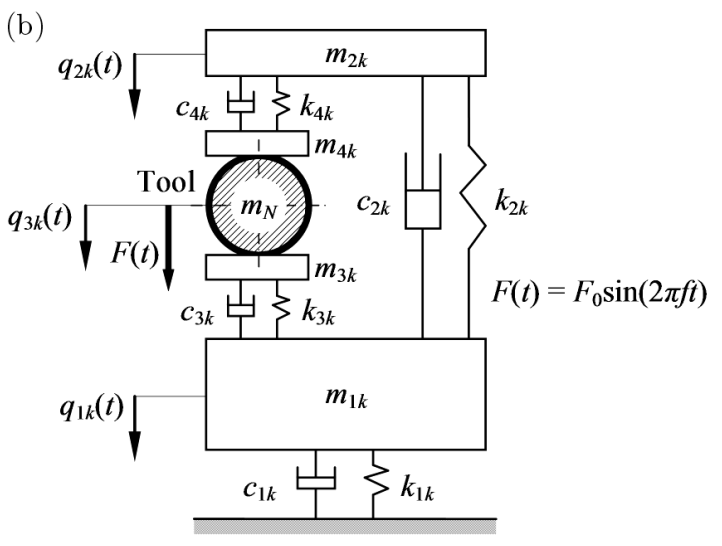

Fig. 2. A synthesis of the ISO 10068:2012-based human physical models with the tool model: (a) model 1 and tool; (b) model 2 and tool (ISO 10068:2012)

The mathematical models of the Human-Tool systems are constructed using generalized coordinates. Since three directions of vibration are taken into account, it is necessary to formulate three differential equations of motion. Hence, a complete analysis of the impact of vibration on the human body (along the $x, y$ and $z$ axes), requires:

a) for the model with two points of reduction (Fig. 2a) - 6 generalized coordinates and 6 differential equations of motion, since the model has 2 two points of reduction and 6 degrees of freedom,

b) for the model with three points of reduction (Fig. 2b) - 9 generalized coordinates and 9 differential equations of motion, since the model has 3 two points of reduction and 9 degrees of freedom.

Since the models of interest have the same structure in each direction of vibrations, in accordance with the ISO standard, it is sufficient to present 2 general differential equations of motion for the model with two points of reduction and 3 general differential equations of motion for the model with three points of reduction. The equations for the $x, y$ and $z$ directions can be obtained by substituting the values of dynamic parameters for each direction, see Table 1 and 2, and introducing generalized coordinates for this direction.

The first step in the formulation of general differential equations involves introduction of generalized coordinates. For the model shown in Fig. 2, the following generalized coordinates are used (Fig. 2a)

$$
\begin{aligned}
& j=1 \Rightarrow q_{1 k}=u_{1 k}(t) \quad- \text { displacement of mass } m_{1 k} \text { in the } k \text {-th direction } \\
& j=2 \Rightarrow q_{2 k}=u_{2 k}(t) \quad-\quad \begin{array}{l}
\text { displacement of mass } m_{2 k} \text { and } m_{N} \text { in the } k \text {-th direction, } \\
\text { where } m_{N} \text { is the mass of the hand-held power tool for each } \\
\text { direction }
\end{array}
\end{aligned}
$$


For the combination of the ISO 10068:2012-based model - model 2 and the tool model (Fig. 2b), the following generalized coordinates are used

$$
\begin{aligned}
& j=1 \quad \Rightarrow \quad q_{1 k}=u_{1 k}(t) \quad-\text { displacement of mass } m_{1 k} \text { in } k \text {-th direction } \\
& j=2 \Rightarrow q_{2 k}=u_{2 k}(t) \quad-\text { displacement of mass } m_{2 k} \text { in } k \text {-th direction } \\
& j=3 \Rightarrow q_{3 k}=u_{3 k}(t) \quad-\text { displacement of mass } m_{3 k}, m_{4 k} \text { and } m_{N} \text { in } k \text {-th direction }
\end{aligned}
$$

After applying the generalized coordinates defined above, the general mathematical model of the Human-Tool system (Fig. 2a), can be written down as

$$
\begin{array}{ll}
j=1 & m_{1 k} \ddot{u}_{1 k}+\left(c_{1 k}+c_{2 k}\right) \dot{u}_{1 k}+\left(k_{1 k}+k_{2 k}\right) u_{k}-c_{2 k} \dot{u}_{2 k}-k_{2 k} u_{2 k}=0 \\
j=2 & \left(m_{2 k}+m_{N}\right) \ddot{u}_{2 k}+c_{2 k} \dot{u}_{2 k}+k_{2 k} u_{2 k}-c_{2 k} \dot{u}_{1 k}-k_{2 k} u_{1 k}=F_{0} \sin (2 \pi f t)
\end{array}
$$

The general mathematical model of the combined model consisting of the ISO 10068:2012-based model and the tool model (Fig. 2b) is given by three equations

$$
\begin{array}{ll}
j=1 & m_{1 k} \ddot{u}_{1 k}+\left(c_{1 k}+c_{2 k}+c_{3 k}\right) \dot{u}_{1 k}+\left(k_{1 k}+k_{2 k}+k_{3 k}\right) u_{1 k}-c_{3 k} \dot{u}_{3 k}-k_{3 k} u_{3 k} \\
& -c_{2 k} \dot{u}_{2 k}-k_{2 k} u_{2 k}=0 \\
j=2 & m_{2 k} \ddot{u}_{2 k}+\left(c_{2 k}+c_{4 k}\right) \dot{u}_{2 k}+\left(k_{2 k}+k_{4 k}\right) u_{2 k}-c_{2 k} \dot{u}_{1 k}-k_{2 k} u_{1 k}-c_{4 k} \dot{u}_{3 k} \\
& -k_{4 k} u_{3 k}=0 \\
j=3 \quad & \left(m_{3 k}+m_{4 k}+m_{N}\right) \ddot{u}_{3 k}+\left(c_{3 k}+c_{4 k}\right) \dot{u}_{3 k}+\left(k_{3 k}+k_{4 k}\right) u_{3 k}-c_{4 k} \dot{u}_{2 k} \\
& -k_{4 k} u_{2 k}-c_{3 k} \dot{u}_{1 k}-k_{3 k} u_{1 k}=F_{0} \sin (2 \pi f t)
\end{array}
$$

General differential equations of motion (2.2) and (2.3) are used to construct energy models of the Human-Tool systems of interest by applying the First Principle of Energy Flow in a Mechanical System (Dobry, 1998, 2001, 2012). This approach enables switching from the conventional dynamic analysis conducted in terms of displacement amplitudes, velocities and accelerations to the energy analysis in terms of energy flow. The general energy model of the Human-Tool system with two points of reduction, Fig. 2a, has the following form

$$
\begin{array}{ll}
j=1 \quad & \int_{0}^{t}\left|m_{1 k} \ddot{u}_{1 k} \dot{u}_{1 k}\right| d t+\int_{0}^{t}\left|\left(c_{1 k}+c_{2 k}\right) \dot{u}_{1 k}^{2}\right| d t+\int_{0}^{t}\left|\left(k_{1 k}+k_{2 k}\right) u_{k} \dot{u}_{1 k}\right| d t \\
& -\int_{0}^{t}\left|c_{2 k} \dot{u}_{2 k} \dot{u}_{1 k}\right| d t-\int_{0}^{t}\left|k_{2 k} u_{2 k} \dot{u}_{1 k}\right| d t=0 \\
j=2 \quad & \int_{0}^{t}\left|\left(m_{2 k}+m_{N}\right) \ddot{u}_{2 k} \dot{u}_{2 k}\right| d t+\int_{0}^{t}\left|c_{2 k} \dot{u}_{2 k}^{2}\right| d t+\int_{0}^{t}\left|k_{2 k} u_{2 k} \dot{u}_{2 k}\right| d t \\
& -\int_{0}^{t}\left|c_{2 k} \dot{u}_{1 k} \dot{u}_{2 k}\right| d t-\int_{0}^{t}\left|k_{2 k} u_{1 k} \dot{u}_{2 k}\right| d t=\int_{0}^{t}\left|F_{0} \sin (2 \pi f t) \dot{u}_{2 k}\right| d t
\end{array}
$$

The general energy model of the second Human-Tool system, Fig. 2b, is given by

$$
\begin{array}{ll}
j=1 \quad & \int_{0}^{t}\left|m_{1 k} \ddot{u}_{1 k} \dot{u}_{1 k}\right| d t+\int_{0}^{t}\left|\left(c_{1 k}+c_{2 k}+c_{3 k}\right) \dot{u}_{1 k}^{2}\right| d t+\int_{0}^{t}\left|\left(k_{1 k}+k_{2 k}+k_{3 k}\right) u_{1 k} \dot{u}_{1 k}\right| d t \\
& -\int_{0}^{t}\left|c_{3 k} \dot{u}_{3 k} \dot{u}_{1 k}\right| d t-\int_{0}^{t}\left|k_{3 k} u_{3 k} \dot{u}_{1 k}\right| d t-\int_{0}^{t}\left|c_{2 k} \dot{u}_{2 k} \dot{u}_{1 k}\right| d t-\int_{0}^{t}\left|k_{2 k} u_{2 k} \dot{u}_{1 k}\right| d t=0 \\
j=2 & \int_{0}^{t}\left|m_{2 k} \ddot{u}_{2 k} \dot{u}_{2 k}\right| d t+\int_{0}^{t}\left|\left(c_{2 k}+c_{4 k}\right) \dot{u}_{2 k}^{2}\right| d t+\int_{0}^{t}\left|\left(k_{2 k}+k_{4 k}\right) u_{2 k} \dot{u}_{2 k}\right| d t \\
& -\int_{0}^{t}\left|c_{2 k} \dot{u}_{1 k} \dot{u}_{2 k}\right| d t-\int_{0}^{t}\left|k_{2 k} u_{1 k} \dot{u}_{2 k}\right| d t-\int_{0}^{t}\left|c_{4 k} \dot{u}_{3 k} \dot{u}_{2 k}\right| d t-\int_{0}^{t}\left|k_{4 k} u_{3 k} \dot{u}_{2 k}\right| d t=0 \\
j=3 \quad & \int_{0}^{t}\left|\left(m_{3 k}+m_{4 k}+m_{N}\right) \ddot{u}_{3 k} \dot{u}_{3 k}\right| d t+\int_{0}^{t}\left|\left(c_{3 k}+c_{4 k}\right) \dot{u}_{3 k}^{2}\right| d t+\int_{0}^{t}\left|\left(k_{3 k}+k_{4 k}\right) u_{3 k} \dot{u}_{3 k}\right| d t \\
& -\int_{0}^{t}\left|c_{4 k} \dot{u}_{2 k} \dot{u}_{3 k}\right| d t-\int_{0}^{t}\left|k_{4 k} u_{2 k} \dot{u}_{3 k}\right| d t-\int_{0}^{t}\left|c_{3 k} \dot{u}_{1 k} \dot{u}_{3 k}\right| d t-\int_{0}^{t}\left|k_{3 k} u_{1 k} \dot{u}_{3 k}\right| d t \\
& =\int_{0}^{t}\left|F_{0} \sin (2 \pi f t) \dot{u}_{3 k}\right| d t
\end{array}
$$


The energy models of two Human-Tool systems (2.4) and (2.5) are solved using a simulation programme implemented in the MATLAB/simulink software. The simulation time t was 300 seconds. Additionally, integration time steps used in the simulation were set to range from a maximum of 0.0001 to a minimum of 0.00001 second, with a tolerance of 0.001 . Simulation-based inputs of the energy of inertia, dissipation and elasticity were used to compare the models. The models were regarded as comparable when the inputs of respective types of energy were equal.

\section{Energy comparison of the human-tool systems}

On the basis of the First Principle of Energy Flow in a Mechanical System (Dobry, 1998, 2001, 2012 ) it is possible to determine the precise amounts of the three kinds of energy for each HumanTool system. Energy inputs of inertia, dissipation and elasticity can be obtained by integrating the absolute values of dynamic forces. In this particular case, these are simply sums in which the absolute values of specific types of power are integrated within simulation time equal to 300 seconds.

For the Human-Tool system based on the model with three points of reduction from ISO 10068:2012 - Fig. 2b, the energy inputs are calculated using the following formulas:

a) energy of inertia for the $k$-th direction, expressed in $[\mathrm{J}]$

$$
E_{3 k-\mathrm{INE}}=\int_{0}^{t}\left|m_{1 k} \ddot{u}_{1 k} \dot{u}_{1 k}\right| d t+\int_{0}^{t}\left|m_{2 k} \ddot{u}_{2 k} \dot{u}_{2 k}\right| d t+\int_{0}^{t}\left|\left(m_{3 k}+m_{4 k}+m_{N}\right) \ddot{u}_{3 k} \dot{u}_{3 k}\right| d t
$$

b) energy of dissipation for the $k$-th direction, expressed in $[\mathrm{J}]$

$$
E_{3 k-\mathrm{DIS}}=\int_{0}^{t}\left|\left(c_{1 k}+c_{2 k}+c_{3 k}\right) \dot{u}_{1 k}^{2}\right| d t+\int_{0}^{t}\left|\left(c_{2 k}+c_{4 k}\right) \dot{u}_{2 k}^{2}\right| d t+\int_{0}^{t}\left|\left(c_{3 k}+c_{4 k}\right) \dot{u}_{3 k}^{2}\right| d t
$$

c) energy of elasticity for the $k$-th direction, expressed in [J]

$$
\begin{aligned}
& E_{3 k-\mathrm{ELA}}=\int_{0}^{t}\left|\left(k_{1 k}+k_{2 k}+k_{3 k}\right) u_{1 k} \dot{u}_{1 k}\right| d t+\int_{0}^{t}\left|\left(k_{2 k}+k_{4 k}\right) u_{2 k} \dot{u}_{2 k}\right| d t \\
& +\int_{0}^{t}\left|\left(k_{3 k}+k_{4 k}\right) u_{3 k} \dot{u}_{3 k}\right| d t
\end{aligned}
$$

For the second Human-Tool system - Fig. 2a, the following formulas are derived to calculate: a) energy of inertia for the $k$-th direction, expressed in $[\mathrm{J}]$

$$
E_{2 k-\mathrm{INE}}=\int_{0}^{t}\left|m_{1 k} \ddot{u}_{1 k} \dot{u}_{1 k}\right| d t+\int_{0}^{t}\left|\left(m_{2 k}+m_{N}\right) \ddot{u}_{2 k} \dot{u}_{2 k}\right| d t
$$

b) energy of dissipation for the $k$-th direction, expressed in $[\mathrm{J}]$

$$
E_{2 k-\text { DIS }}=\int_{0}^{t}\left|\left(c_{1 k}+c_{2 k}\right) \dot{u}_{1 k}^{2}\right| d t+\int_{0}^{t}\left|c_{2 k} \dot{u}_{2 k}^{2}\right| d t
$$

c) energy of elasticity for the $k$-th direction, expressed in $[\mathrm{J}]$

$$
E_{2 k-\mathrm{ELA}}=\int_{0}^{t}\left|\left(k_{1 k}+k_{2 k}\right) u_{1 k} \dot{u}_{1 k}\right| d t+\int_{0}^{t}\left|k_{2 k} u_{2 k} \dot{u}_{2 k}\right| d t
$$


Table 3 presents the amounts of three types of energy, the combined energy input in each direction and the total energy input for the two Human-Tool systems of interest.

Table 3. Energy flow in the models of the Human-Tool systems

\begin{tabular}{|l|c|c|c|c|c|c|c|}
\hline \multirow{2}{*}{ Model } & \multicolumn{3}{|c|}{ Model 1 } & \multicolumn{3}{c|}{ Model 2 } \\
& 2 points of reduction & 3 points of reduction \\
\hline \multicolumn{2}{|c|}{ Direction } & $x$ & $y$ & $z$ & $x$ & $y$ & $z$ \\
\hline \hline \multirow{2}{*}{$\begin{array}{l}\text { Energy } \\
\text { input of }\end{array}$} & inertia $E_{\mathrm{INE}}(t)[\mathrm{J}]$ & 3749 & 4211 & 4406 & 3782 & 4078 & 4309 \\
\cline { 2 - 8 } & dissipation $E_{\mathrm{DIS}}(t)[\mathrm{J}]$ & 2047 & 1266 & 2669 & 3591 & 1195 & 3967 \\
\cline { 2 - 8 } & elasticity $E_{\mathrm{ELA}}(t)[\mathrm{J}]$ & 5 & 813 & 2226 & 486 & 1107 & 8950 \\
\hline Energy input - in one direction $[\mathrm{J}]$ & 5801 & 6290 & 9301 & 7859 & 6380 & 17226 \\
\hline \multicolumn{3}{|c|}{21392} & \multicolumn{5}{c|}{31465} \\
\hline
\end{tabular}

Using the values obtained by applying the energy method, it is possible to compare the two models from ISO 10068:2012. Figure 3 shows the percentages of the three kinds of energy in the two models in three directions. The percentages are calculated as ratios of energy kinds for the model with 3 points of reduction to their corresponding values for the model with 2 points of reduction. The relation can be written as

$$
D_{K}=\frac{E_{3 k-\mathrm{X}}}{E_{2 k-\mathrm{X}}} \cdot 100 \%
$$

where: $E_{3 k-\mathrm{X}}$ - energy input of inertia, dissipation and elasticity in the whole system, calculated as a sum of energy inputs from all points of reduction and obtained by adopting model 2 with three points of reduction - expressed in $[\mathrm{J}], E_{2 k-\mathrm{X}}$ - energy input of inertia, dissipation and elasticity in the whole system, calculated as a sum of energy inputs from all points of reduction and obtained by adopting model 1 with two points of reduction - expressed in [J].

A value exceeding $100 \%$ means that the energy input in model $b$ is higher than in model $a$ - see Fig. 2.

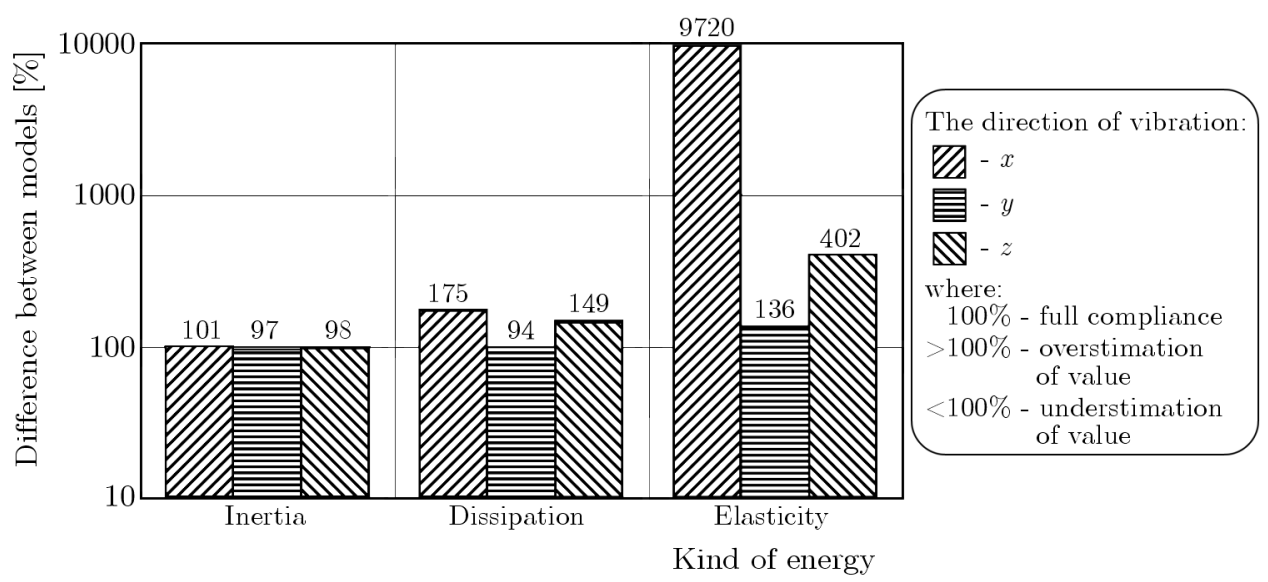

Fig. 3. Energy difference between the models depending on the direction of vibrations

The results shown in Fig. 3 indicate a lack of similarity between the models. The degree of similarity depends on two factors. The first one is the kind of energy. In this respect, the differences between the models range from:

- energy of inertia - between 1 and $3 \%$,

- energy of dissipation - between 6 and $75 \%$,

- energy of elasticity - between 36 and $9620 \%$. 
It should be noted that the 96 -fold underestimation of the energy of elasticity evidently results from the model structure. With respect to the model with two points of reduction (Fig. 2a), the structure along the $x$ direction of vibrations differs from the structure along the other directions. The authors of the model choose not to account for elasticity along this direction - denoted as $k_{2 x}$ (Table 1). The value of the dynamic parameter for this element equals 0 , which contributes to model simplification and results in a considerably lower flow of energy through the model.

This fact does not affect the order of energy kinds in terms of the degree of similarity between the models, which is the same in all directions, with the highest level of equivalence for the energy of inertia, followed by the energy of dissipation and the lowest for the energy of elasticity.

The second factor which affects the degree of similarity is the direction of vibrations. The highest level of equivalence between the models is observed in the $y$ direction - Fig. 3. In this case, differences in energy inputs between the levels are $3 \%$ for inertia, $6 \%$ for dissipation and $36 \%$ for elasticity.

For other directions, the order is not so consistent. In terms of the kind of energy, there is clearly more similarity between the models along the $z$ direction than in the $x$ direction.

The next aspect of the analysis is related to the combined energy input along one direction. If one looks only at the directional flow of the combined energy input consisting of the three kinds of energy, the resulting order is reverse. Figure 4 shows the percentage difference in combined energy inputs along the three directions between the two models.

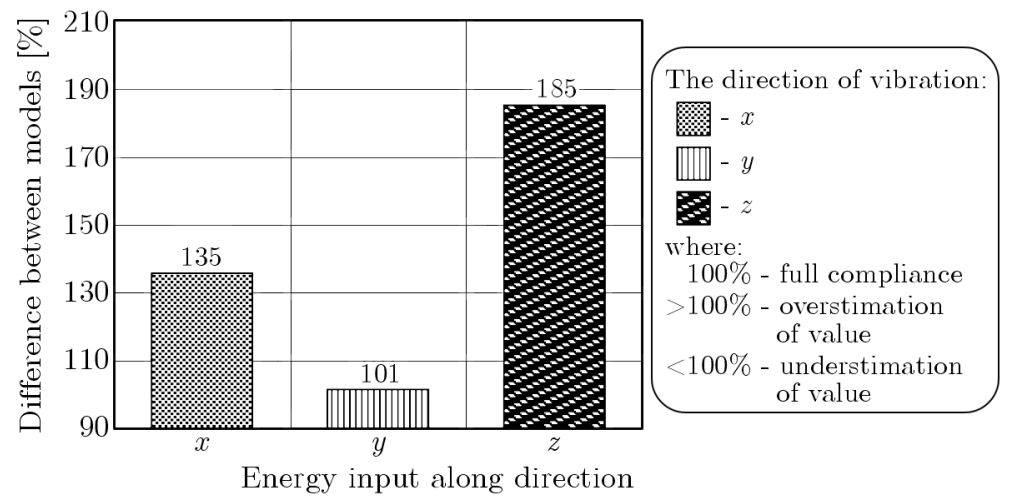

Fig. 4. The influence of the direction of vibrations on the increase in combined energy input along one direction

The two models of interest can also be analysed in terms of total energy input, which is calculated by summing up the directional flows for each model. From this point of view, the flow of energy in the model with three points of reduction is higher by $47 \%$ compared with the model with two points of reduction, see Table 3 . This means that the human model chosen in the analysis plays a crucial role in determining the level of protection that is intended for the human operator of hand-held power tools: the technical standards that must be met by hand-held tools are significantly higher when the assessment of the impact of vibrations is based on the model with three points of reduction (Fig. 2b) compared to those based on the model with two points of reduction (Fig. 2a).

If we assume the acceptable tolerance between the models of no more than $5 \%$, we considerably limit the extent to which the two models can be used interchangeably. With such a margin of error, the only aspect of the two models that can be regarded as comparable is the energy of inertia, see Fig. 3. Consequently, the models are not energy equivalent and can yield incomparable results in the theoretical analysis of the impact of vibrations on the human body. 


\section{Conclusions}

Based on the above energy comparison of the Human-Tool models, we must conclude that the two models display considerable differences in terms of the similarity criterion, which is the equivalence between the predicted values of the three kinds of energy. The simulation results reveal the highest degree of similarity with respect to the energy of inertia (Fig. 3) with a difference of no more than $3 \%$. There is no similarity in terms of the energy of dissipation or elasticity.

The differences are also manifested in the energy levels predicted by the models along the $x, y$ and $z$ directions (Fig. 4). In this case, the highest degree of equivalence can be observed along the $y$ direction, with a difference of only $1 \%$. It should be remembered, however, that the models are characterised by different internal structures. It can therefore be concluded that it is the internal structure of the models that directly affects the level of equivalence between the three kinds of energy. It is also worth pointing out that for both models the highest energy input can be observed along the $z$ direction, which is shown in Table 3. This suggests that it is the most crucial direction from the point of view of the impact of vibrations of the human body.

When analysed in terms of total energy input along the three directions, the models differ from each other by as much as 47\%. This means that the ISO 10068:2012 model with three points of reduction, see Fig. $2 \mathrm{~b}$, used in the theoretical study of the impact of vibrations on the human body will result in raising the technical requirements used in the assessment of power tools, which has to do with the increased flow of energy predicted by this model. It can be expected that the use of this model in the energy assessment of power tools will increase the requirements concerning their vibroisolation.

Acknowledgments

The study was co-financed by the Ministry of Science and Higher Education and was part of the research project (02/21/DSMK/3458) entitled: Energy, diagnostic and acoustic problems in vibroacoustics.

\section{References}

1. Cannon R.H. JR., 1973, Dynamics of Physical Systems (in Polish), Wydawnictwa Naukowo-Techniczne

2. Dobry M.W., 1998, Optimization of the Energy Flow in the Human-Tool Base System (in Polish), Rozprawa habilitacyjna, Seria "Rozprawy" nr 330, ISSN 0551-6528, Wydawnictwo Politechniki Poznańskiej, Poznań

3. Dobry M. W., 2001, Energy diagnostics and assessment of dynamics of mechanical and biomechatronics systems, Machine Dynamics Problems, 25, 35-54

4. Dobry M.W., 2012, Fundamentals of Energy Diagnostics of Mechanical and Biomechanical Systems (in Polish), Wydawnictwo Naukowe Instytutu Technologii Eksploatacji - PIB, Radom

5. Dobry M.W., Hermann T., 2014, Comparison of human physical models specified in ISO 10068:2012 based on the distribution of power, Vibrations in Physical Systems, 26, 49-56

6. Dobry M.W., Hermann T., 2015, A comparison of human physical models based on the distribution of power in a dynamic structure in the case of hand-arm vibrations, Journal of Theoretical and Applied Mechanics, 53, 1, 3-13

7. Dong R.G., Dong J.H., Wu J.Z., Rakheja S., 2007, Modelling of biodynamic responses distributed at the fingers and the palm of the human hand-arm system, Journal of Biomechanics, 40, 2335-2340

8. Dong R.G., Rakheja S., McDowell T.W., Welcome D.E., Wu J.Z., 2010, Estimation of the biodynamic responses distributed at fingers and palm based on the total response of the hand-arm system, International Journal of Industrial Ergonomics, 40, 425-436 
9. Dong R.G., Welcome D.E., McDowell T.W., Wu J.Z., 2013, Modelling of the biodynamic responses distributed at the fingers and palm of the hand in three orthogonal directions, Journal of Sound and Vibration, 332, 1125-1140

10. Griffin M.J., 1990, Handbook of Human Vibration, Academic Press, London

11. ISO 10068:1998, Mechanical vibration and shock - free, mechanical impedance of the human handarm system at the driving point

12. ISO 10068:2012, Mechanical vibration and shock - mechanical impedance of the human hand-arm system at the driving point

13. KsiĄżEK A.M., 1996, Analysis of the existing biodynamic hand-arm models to isolation of a human - operator from vibrations emitted by the hand-held tools (in Polish), Czasopismo Techniczne, Wydawnictwo Politechniki Krakowskiej, 87-114

14. Meltzer G., 1981, A vibration model for the human hand-arm-system, Studies in Environmental Science, 13, 210-221

15. Rakheja S., Wu J.Z., Dong R.G., Schopper A.W., 2002, A comparison of biodynamic models of the Human hand-arm system for applications to hand-held power tools, Journal of Sound and Vibration, 249, 55-82

16. Reynolds D.D., Soedel W., 1972, Dynamic response of the hand-arm system to a sinusoidal input, Journal of Sound and Vibration, 21, 339-353

17. ŻóŁtowski B., 2002, Study of the Dynamics of Machines (in Polish), Markar - B.Ż., Bydgoszcz 